\title{
The Role of sLZIP in Transcriptional Regulation of c-Jun and Involvement in Migration and Invasion of Cervical Cancer Cells
}

\author{
Eunsoo Park ${ }^{\mathrm{a}, \mathrm{b}}$ Hyereen Kang ${ }^{\mathrm{a}, \mathrm{b}}$ Jeonghan Kim ${ }^{\mathrm{a}} \quad$ Jesang Ko

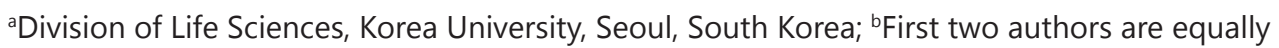 \\ contributed
}

\section{Key Words}

Cervical cancer $•$ sLZIP $•$ Migration $・$ Invasion $\cdot$ c-Jun $•$ MMP-9

\begin{abstract}
Background/Aims: Matrix metalloproteinase-9 (MMP-9) plays an important role in tumor invasion and metastasis through the breakdown of extracellular matrix. The c-Jun protein, a major component of the AP-1 transcription factor, is elevated in various cancers. Small leucine zipper protein (sLZIP) is a member of the leucine zipper transcription factor family. Although sLZIP is known to be involved in cancer cell migration and invasion, its biological roles in cancer development and the cellular target genes are not fully understood. In this study, we investigated the role of sLZIP in c-Jun expression, and their effects on expression of MMP-9 and migration of cervical cancer cells. Methods and Results: SLZIP up-regulates transcription of c-Jun by binding directly to the CRE region in the c-Jun promoter. Elevated c-Jun due to SLZIP leads to activation of MMP-9 transcription by interaction with the AP-1 binding site in the MMP-9 promoter. C-Jun siRNA repressed migration and invasion of cervical cancer cells, whereas SLZIP recovered migration and invasion of cells transfected with c-Jun siRNA. Immunohistochemical analysis results revealed a significant correlation between the expressions of sLZIP and MMP-9 in clinical cervical specimens. Conclusion: These results indicate that sLZIP plays a role in expression of c-Jun, and migration and invasion of cervical cancer cells via regulation of MMP-9 transcription.
\end{abstract}




\section{Cellular Physiology and Biochemistry}

Cell Physiol Biochem 2014;33:151-164

\begin{tabular}{l|l}
\hline DOI: $10.1159 / 000356658$ & (c) 2014 S. Karger AG, Basel
\end{tabular}

www.karger.com/cpb

Park et al.: Role of sLZIP in Migration and Invasion of Cervical Cancer Cells

\section{Introduction}

Matrix metalloproteinases (MMPs) are a large family of zinc-dependent endopeptidases that are associated with breakdown of the extracellular matrix in a large range of ordinary and pathological conditions, including inflammation, tissue repair, tumor invasion, and metastasis [1-3]. MMP-9 is a $92 \mathrm{kDa}$ type IV collagenase and is well-characterized as the most prominent MMP involved in inflammation and tumorigenesis [1]. MMP-9 is expressed at high levels in a variety of cancers, including glioma, breast, and lung cancers, whereas it is expressed at low levels under normal conditions [4, 5]. MMP-9 is implicated in the proliferation and growth of primary tumors, including prostate carcinoma, lymphoma, neuroblastoma and glioblastoma [6, 7]. Inhibition of MMP-9 expression strongly reduces the metastatic potential [8]. The 5'-flanking region of the MMP-9 promoter contains several binding sites for AP-1, SP-1, NF- $\mathrm{KB}$, and CRE that are important for regulation of MMP-9 activity [9]. MMP-9 also plays a critical role in tissue remodeling, tumor invasion, and metastasis as a target molecule of AP-1 [10-12].

c-Jun, a major component of the AP-1 transcription factor, mediates several cellular processes, including proliferation and survival. c-Jun acts as an oncogene for many cell types and expression of c-Jun is elevated in many types of cancer [11]. c-Jun affects the antiproliferative activity of p53 by direct repression of p53 transcription [13], and cooperates with Ras in tumor cell proliferation [14]. In prostate cancer cells, c-Jun promotes androgen receptor transactivation and cell proliferation [15]. c-Jun is strongly expressed in skin cancer and inhibition of c-Jun is accompanied by suppressed expression of MMP-2 and MMP-9 [16]. c-Jun also mediates transcriptional regulation in response to a variety of stimulants. c-Jun modulates the TNF- $\alpha$ and TGF- $\beta$ signaling pathways, both of which are implicated in liver tumor development $[17,18]$. Transcription of PMA-induced osteopontin is regulated by c-Jun, which leads to cervical tumor growth [19]. c-Jun stimulates transactivation of MMP-9 as a cofactor of $\mathrm{p} 38 \gamma$ to promote colon cancer invasion [20].

The human leucine zipper protein (LZIP) is a basic leucine zipper transcription factor of the CRE/ATF gene family that is ubiquitously expressed in various cell types [21]. LZIP contains a basic leucine zipper motif, a potent $\mathrm{N}$-terminal transcriptional activation domain, and a putative transmembrane domain, and is known to be involved in cell growth and proliferation [22, 23]. Small LZIP (sLZIP), an isoform of human LZIP, functions as a negative regulator of the glucocorticoid receptor (GR), leading to suppression of the gene expression that is induced via the glucocorticoid-mediated GR transactivation pathway [24]. sLZIP also regulates ADP-ribosylation factor 4 (ARF4) expression in response to PMA, leading to activation of the AP-1 promoter, and breast cancer cell migration [25]. Although sLZIP is involved in migration and invasion of cervical cancer cells [26], the cellular target genes and biological roles of sLZIP in cancer development are not fully understood.

In this study, the role of sLZIP in c-Jun expression, subsequent regulation of MMP-9 activity, and migration of cervical cancer cells was investigated. sLZIP up-regulates c-Jun expression at the transcriptional level by binding directly to the CRE (-1050/-1034) region of the c-Jun promoter. Increased c-Jun expression due to sLZIP acts to enhance the activity of MMP-9, and migration and invasion of cervical cancer cells. sLZIP probably contributes to cervical cancer progression via regulation of c-Jun expression and MMP-9 activity.

\section{Materials and Methods}

\section{Materials}

Dulbecco's modified Eagle's medium (DMEM), RPMI 1640, and fetal bovine serum (FBS) were purchased from Invitrogen (Carlsbad, CA). Anti-c-Jun and anti- $\alpha$-tubulin antibodies were from Santa Cruz Biotechnology (Santa Cruz, CA). Scrambled control, human sLZIP and c-Jun siRNAs were purchased from 


\section{Cellular Physiology and Biochemistry}

Cell Physiol Biochem 2014;33:151-164

DOI: 10.1159/000356658

Publisned online: January 24, 2014

(C) 2014 S. Karger AG, Basel

www.karger.com/cpb

Park et al.: Role of sLZIP in Migration and Invasion of Cervical Cancer Cells

Bioneer (Daejeon, Korea). Lipofectamine 2000 reagent was obtained from Invitrogen (Carlsbad, CA). Luciferase assay system was purchased from Promega Corporation (Madison, WI). 3-(4,5-dimethylthiazol2-yl)-2,5-diphenyltetrazolium bromide (MTT) was obtained from Sigma (St. Louis, MO).

\section{Cell culture and transient transfection}

HeLa and SiHa cells were maintained in DMEM supplemented with $10 \%$ heat-inactivated FBS, penicillin $(100 \mathrm{U} / \mathrm{ml})$ and streptomycin $(100 \mu \mathrm{g} / \mathrm{ml})$ at $37^{\circ} \mathrm{C}$ in $5 \% \mathrm{CO}_{2}$ incubator. LNCaP, DU145, PC3, MCF7, A549 and HepG2 cells were grown in RPMI 1640 supplemented with 10\% heat-inactivated FBS, penicillin $(100 \mathrm{U} / \mathrm{ml})$ and streptomycin $(100 \mu \mathrm{g} / \mathrm{ml})$. Cells were seeded into 6-well plates at a density of $5 \times 10^{5}$ cells / well. After $24 \mathrm{~h}$ of incubation, cells were transfected with the experimental plasmids using lipofectamine 2000 reagent according to the manufacturer's instruction.

\section{Electrophoretic mobility shift assay}

The oligonucleotide was labeled with $\left[\gamma^{-32} \mathrm{P}\right] \mathrm{ATP}$ using T4 polynucleotide kinase and incubated with purified His-sLZIP protein for $30 \mathrm{~min}$. The protein-DNA complexes were separated from free probes by electrophoresis on a $4 \%$ polyacrylamide gel. For competition assay, binding reactions were incubated with a 50 to 100 -fold molar excesses of unlabeled oligonucleotide for $20 \mathrm{~min}$. For supershift assay, anti-His antibody was added to the reaction mixture for an additional $30 \mathrm{~min}$ at room temperature.

\section{Chromatin immunoprecipitation assay}

Approximately $1 \times 10^{7}$ cells were used per sample. HeLa cells were fixed with $1 \%$ formaldehyde in the medium for $10 \mathrm{~min}$ at $25^{\circ} \mathrm{C}$, and glycine was added to a final concentration of $0.125 \mathrm{M}$ for 5 min to stop cross-linking. Cells were scraped into PBS and centrifuged at $1,000 \times g$ for $5 \mathrm{~min}$ at $4^{\circ} \mathrm{C}$. Chromatin samples were co-precipitated with HA antibody. The -1274/-1034 region of the c-Jun promoter was amplified from the prepared DNA samples using the specific primers: (F) 5'-GGCCGGGAAAAACGGCCCGG-3' and (R) 5'-ATGATGTCACCCCAAGGCCT-3'.

\section{Western blot analysis}

Transfected cells with the experimental plasmids were scraped and washed with ice-cold PBS. Cells were resuspended in RIPA lysis buffer containing protease inhibitors. The suspension was centrifuged at $13,000 \times g$ for $20 \mathrm{~min}$ at $4^{\circ} \mathrm{C}$. Protein samples were separated by a $10 \%$ SDS-polyacrylamide gel electrophoresis and transferred to nitrocellulose membranes. The blots were incubated with anti-c-Jun, anti-sLZIP, anti-GST and anti- $\alpha$-tubulin antibodies. Membranes were processed using chemiluminescence detection reagent (Pierce, Rockford, IL).

\section{cDNA preparation for PCR amplification}

Total RNA was prepared from transfected cells with Trizol (Invitrogen, Carlsbad, CA) according to the manufacturer's instructions. The cDNA was synthesized from $2 \mu \mathrm{g}$ of total RNA using Accupower RT Premix (Bioneer, Daejeon, Korea). RT-PCR was performed with the following oligomers: c-Jun, (F) 5'-TAACCTCACGTGAAGTGACG-3' and (R) 5'-GGCTTTAGTTCTCGGACACT-3'; sLZIP (F) 5'-AGCAGCAGCATGTACTCCTCT-3' and (R) 5'-CTAGCCTGAGTATCTGTCCT-3'; GAPDH (F) 5'-CACCACCATGGAGAAGGCT-G-3' and (R) 5'-TTGTCATGGATGACCTTGGCCAGG-3'. The PCR products were electrophoresed on $1 \%(\mathrm{w} / \mathrm{v})$ agarose gel containing ethidium bromide. The band intensity was analyzed with UV image analyzer (Vilber Lourmat, Germany).

\section{Luciferase reporter gene activity assay}

HeLa and SiHa cells were cultured in 12-well plates at a density of $2 \times 10^{5}$ cells/well. Cells were cotransfected with the MMP-9-luciferase reporter gene plasmid, sLZIP and si-c-Jun. After $24 \mathrm{~h}$, cells were lysed with the reporter lysis buffer. Luciferase activity was determined using the Luciferase Assay system (Promega corporation, Madison, WI) and recorded in a Luminometer 20/20n (Turner BioSystems, Sunnyvale, CA) according to the manufacturer's instruction. Luciferase activity was normalized with $\beta$-galactosidase activity. For $\beta$-galactosidase assay, pSV- $\beta$-galactosidase was co-transfected with the luciferase reporter gene. Cell extracts were assayed for $\beta$-galactosidase activity using $\beta$-galactosidase enzyme assay system (Promega) and analyzed by DU530 spectrophotometer (Beckman Instruments, Fullerton, CA). 


\section{Cellular Physiology and Biochemistry}

Cell Physiol Biochem 2014;33:151-164

DOI: 10.1159/000356658

(C) 2014 S. Karger AG, Basel

www.karger.com/cpb

Park et al.: Role of sLZIP in Migration and Invasion of Cervical Cancer Cells

Wound healing assay

Cervical cancer cells were grown in 6-well culture plates and wounded with P-10 pipette tip. After scratching, cells were washed with fresh medium and added $30 \%$ conditioned media (CM) mixture. Images were obtained at the indicated time points to compare the cell migration for the wound closure.

Invasion assay

Matrigel invasion assay was used to assess the invasiveness of cervical cancer cells. Transwell inserts with $8.0-\mu \mathrm{m}$ pore size were coated with Matrigel (BD BioScience). Matrigel was diluted with serum-free DMEM and solidified overnight at $37^{\circ} \mathrm{C}$. Approximately $1 \times 10^{5}$ cells in $500 \mu \mathrm{l}$ of serum-free DMEM were placed onto upper chamber per well. The lower chamber was filled with 30\% CM mixture. After $48 \mathrm{~h}$ incubation, non-invasive cells were removed by wiping with cotton-tipped swabs and invasive cells were stained with Diff-Quick staining solution (Baxter, Deerfield, IL) according to the manufacturer's instructions. Five fields of cells were counted in each well and the results were numerically averaged and counted.

\section{Cell proliferation assay}

Cell proliferation was assessed by an MTT method. After $24 \mathrm{~h}$ of transfection, $5 \times 10^{3}$ cells were seeded in 96-well plates per well. MTT was dissolved in medium and added to a final concentration of $500 \mu \mathrm{g} / \mathrm{ml}$. Cells were then incubated for $2 \mathrm{~h}$ at $37^{\circ} \mathrm{C}$ in the dark. The formazan product was dissolved by adding $100 \mu \mathrm{l}$ DMSO to each well. Absorbance was measured at $595 \mathrm{~nm}$.

\section{Gelatin zymography}

MMP-9 activity was presented and measured by a gelatin zymography. Cervical cancer cells were grown in 6-well plates at a density of $5 \times 10^{5}$ cells/well, and transfected cells were cultured in serum-free medium for $48 \mathrm{~h}$. Collected CM were mixed $1: 1$ with $2 \times$ substrate gel sample buffer $(0.5 \mathrm{M}$ Tris- $\mathrm{HCl}, \mathrm{pH} 6.8$, glycerol, $10 \%$ (w/v) SDS, $0.1 \%$ bromophenol blue) and stood for $10 \mathrm{~min}$ at room temperature. The samples were loaded onto a $10 \%$ SDS-polyacrylamide gel containing $0.1 \%$ gelatin $(1 \mathrm{mg} / \mathrm{ml})$. The gel was incubated in the zymogram renaturing buffer containing 2.5\% Triton X-100 (v/v) with gentle agitation for 30 min at room temperature. The gel was rinsed with developing buffer $\left(50 \mathrm{mM}\right.$ Tris- $\mathrm{HCl}, 0.2 \mathrm{M} \mathrm{NaCl}, 5 \mathrm{mM} \mathrm{CaCl}_{2}$, and $0.02 \%$ Brij 35 ) for $30 \mathrm{~min}$, then replaced with fresh buffer and incubated at $37^{\circ} \mathrm{C}$ for overnight. After incubation, the gel was stained with $0.5 \%$ Coomassie brilliant blue R-250 and destained with destaining solution until the areas of protease activity appear as clear bands.

\section{Immunohistochemistry}

Immunohistochemistry was performed using a human cervical tissue array kit, containing 55 carcinomas and 5 normal tissue specimens (SuperBioChips Laboratories, Seoul, Korea). Normal and cervical cancer tissues were immunostained for SLZIP and MMP-9 using anti-sLZIP and anti-MMP-9 antibodies. All samples were fixed with $10 \%$ formalin, embedded in paraffin, sectioned and then HE-stained for histological analysis. Representative data were examined to assess the histopathological characteristics of cervical cancer.

\section{Statistical analysis}

Data were presented as the mean \pm SEM. Student's $t$-test was used for two-group comparisons. Statistical evaluation was carried out by using one-way ANOVA. Data were considered statistically significant when $p<0.05$. All statistical analysis was performed using a computer program Prism (Graphpad Software, La Jolla, CA).

\section{Results}

SLZIP induces c-Jun expression in cervical cancer cells

To investigate the role of SLZIP in expression of c-Jun and cancer development, we first examined the effect of sLZIP on the protein expression of c-Jun in various cancer cells. Cancer cells, including cervical, prostate, breast, lung, and liver cancers, were transfected with sLZIP, and the protein level of c-Jun was determined using Western blotting. sLZIP 


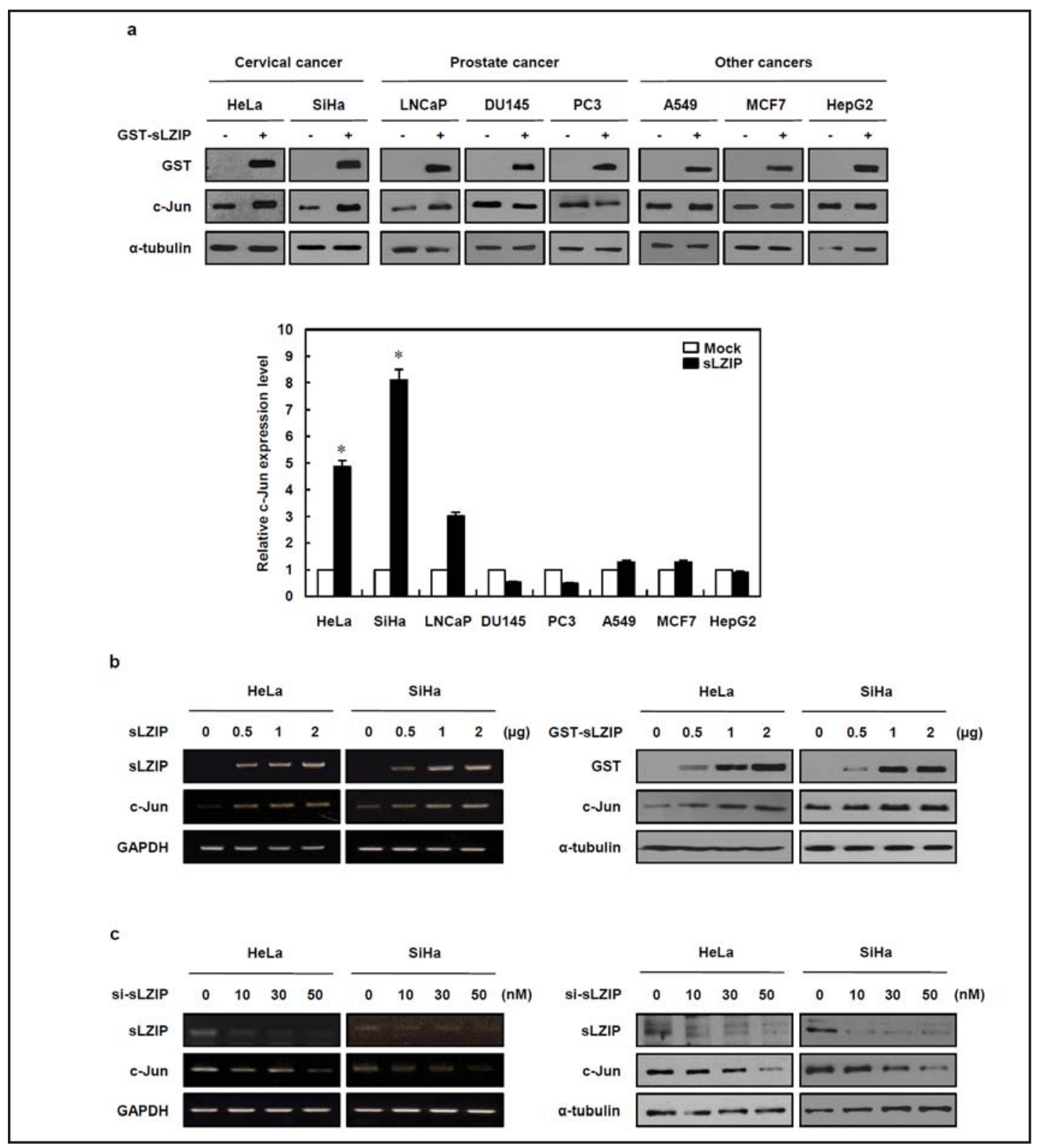

Fig. 1. sLZIP induces c-Jun expression in cervical cancer cells. (a) Various cancer cell lines were transfected with GST-sLZIP $(2 \mu \mathrm{g})$. After $24 \mathrm{~h}$ of transfection, cell lysates were separated on a $10 \%$ SDS-polyacrylamide gel, and transferred to nitrocellulose membranes. The protein level was determined by immunoblotting using specific antibodies. The membranes were stripped and reprobed with anti- $\alpha$-tubulin antibody. $\alpha$-tubulin was used as an endogenous control. ${ }^{*} p<0.05$. All experiments were performed in triplicate and the bar represents the mean \pm SEM. (b) SLZIP expression plasmids $(0,0.5,1$, and $2 \mu \mathrm{g})$ or (c) si-sLZIP $(0$, 10,30 , and $50 \mathrm{nM}$ ) were transfected into HeLa and SiHa cells. Total RNA extracts prepared from transfected cells were assessed by RT-PCR using specific primers. Equal volumes of each PCR product were analyzed by $1 \%$ agarose gel electrophoresis. GAPDH was amplified as an endogenous control. Protein extracts were subjected to $10 \%$ SDS-PAGE analysis and transferred to nitrocellulose membranes. The protein level was determined by immunoblotting using specific antibodies and $\alpha$-tubulin was used as an internal control.

increased c-Jun expression by 5-8 fold in HeLa and SiHa cervical cancer cells, compared with a control (Fig. 1a). sLZIP also increased c-Jun expression in LNCaP prostate cancer cells, whereas c-Jun expression was decreased by sLZIP in DU145 and PC3 cells (Fig. 1a). sLZIP had no effect on expression of c-Jun in other cancer cells (Fig. 1a). Since the effect of sLZIP 


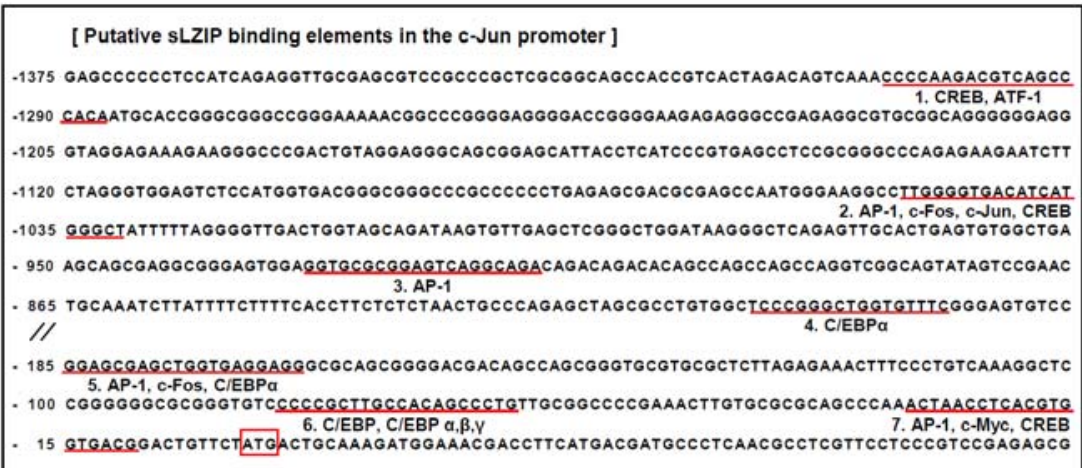

b
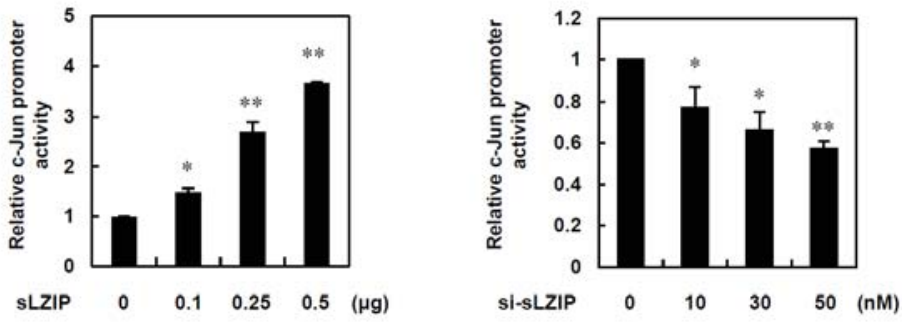

c

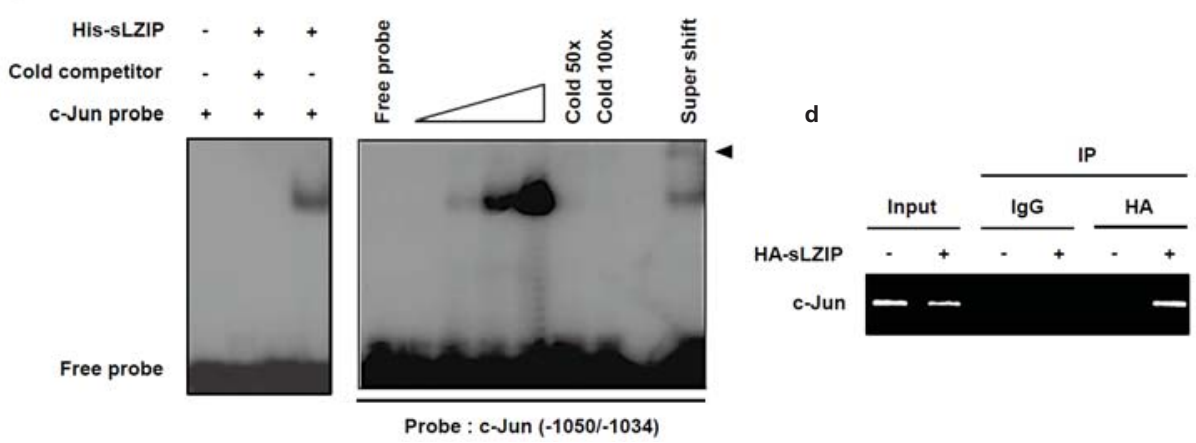

Fig. 2. sLZIP binds directly to the CRE region in the c-Jun promoter. (a) Transcriptional regulatory elements of the c-Jun promoter. The various proteins that regulate transcription of c-Jun are shown relative to their binding sites on the promoter. The abbreviations used are as follows: CREB, cAMP regulatory element binding protein; ATF-1, activating transcription factor-1; C/EBP, CAAT/enhancer binding protein; AP-1, activator protein-1. (b) HeLa cells were transfected with the c-Jun reporter gene plasmid $(0.5 \mu \mathrm{g})$, the indicated amounts of sLZIP or si-sLZIP, and $\beta$-galactosidase $(0.2 \mu \mathrm{g})$. After $24 \mathrm{~h}$, cells were harvested and analyzed for c-Jun luciferase activity. Luciferase activity was normalized by $\beta$-galactosidase activity. Results are expressed as the mean \pm SEM of three experiments performed in duplicate. ${ }^{*} p<0.05,{ }^{* *} p<0.01$. All experiments were performed in triplicate and the bar represents the mean \pm SEM. (c) EMSA was performed using purified His-sLZIP protein and ${ }^{32} \mathrm{P}-$-labeled c-Jun probe. An oligonucleotide containing the CRE region in the c-Jun promoter (-1050/-1034) was incubated with 3, 5, and $10 \mu \mathrm{g}$ of His-sLZIP protein. To perform the competition assay, unlabeled c-Jun probe was used with 50 - and 100 -fold excesses. Arrows indicate the shift corresponding to the position of the His-sLZIP-DNA complex. (d) Chromatin samples were obtained from sLZIP overexpressing HeLa cells, and immunoprecipitated using anti-HA antibody. Rabbit IgG was used as a negative control. The precipitated DNA was subjected to PCR with the primers specific for the target region $(-1274 /-1035)$. One aliquot of input DNA was used as a positive control.

on c-Jun expression was apparent in cervical cancer cells, the role of sLZIP in expression of c-Jun and cervical cancer development was targeted. We examined the dose dependency of sLZIP in c-Jun expression. HeLa and SiHa cells were transfected with sLZIP, and the mRNA 


\section{Cellular Physiology and Biochemistry}

Cell Physiol Biochem 2014;33:151-164

\begin{tabular}{l|l}
\hline DOI: $10.1159 / 000356658$ & (c) 2014 S. Karger AG, Basel
\end{tabular}

www.karger.com/cpb

Park et al.: Role of sLZIP in Migration and Invasion of Cervical Cancer Cells

and protein expression levels of c-Jun were examined. Results revealed that sLZIP induces c-Jun expression in a dose-dependent manner at both the mRNA and protein levels (Fig. 1b). For confirmation, sLZIP was depleted using siRNA. The level of sLZIP was effectively decreased due to siRNA for sLZIP (si-sLZIP) (Fig. 1c). HeLa and SiHa cells transfected with si-sLZIP exhibited decreased c-Jun expression at both the mRNA and protein levels (Fig. 1c). These results indicate that sLZIP induces c-Jun expression at the transcriptional level in cervical cancer cells.

\section{SLZIP binds directly to the CRE region in the c-Jun promoter}

Since sLZIP induces c-Jun expression, we investigated whether sLZIP regulates the c-Jun transcriptional activation. c-Jun promoter sequences were analyzed using the Transcription Element Search System (TESS). Several potential sLZIP binding sites are located on the c-Jun promoter (Fig. 2a). HeLa cells were transfected with sLZIP and the transcriptional activity of c-Jun was assessed using a luciferase assay. sLZIP increased the c-Jun promoter activity, and knockdown of sLZIP using a specific siRNA decreased the c-Jun promoter activity in a dosedependent manner, compared with a control (Fig. 2b). These results indicate that sLZIP contributes to regulation of the c-Jun transcriptional activity. To examine the DNA binding ability of sLZIP to the c-Jun promoter, an EMSA was performed using the purified His-sLZIP protein and ${ }^{32} \mathrm{P}$-labeled probes containing various transcription factor binding motifs on the 5' flanking regions of c-Jun in HeLa cells. Results indicated that sLZIP binds directly to the CRE region ( -1050 to -1034$)$ in the c-Jun promoter (Fig. 2c). However, sLZIP did not bind to other elements of the c-Jun promoter. The binding specificity of sLZIP to the CRE region was confirmed using a competition assay. Binding of SLZIP to the CRE ( -1050 to -1034$)$ in the c-Jun promoter was increased in a dose-dependent manner (Fig. 2c). The sLZIP-CRE complex was not formed in the presence of 50- and 100-fold molar excesses of the unlabeled probe (Fig. 2c). The sLZIP complex was supershifted by addition of the anti-His antibody, indicating that binding of sLZIP to the CRE $(-1050$ to -1034) in the c-Jun promoter is specific (Fig. 2c). We also performed a ChIP assay to examine recruitment of sLZIP to the CRE region in the c-Jun promoter. HeLa cells were transfected with HA-sLZIP, and resulting chromatin samples were immunoprecipitated using the HA antibody. Results indicated that sLZIP is recruited to the CRE region in the c-Jun promoter (Fig. $2 \mathrm{~d}$ ). Thus, sLZIP binds directly to the CRE (-1050 to -1034) in the c-Jun promoter, leading to activation of c-Jun transcription.

\section{Elevated c-Jun levels due to SLZIP expression up-regulate MMP-9 transcription}

To examine the effect of c-Jun induced by SLZIP on MMP-9 transcription, an MMP9 luciferase reporter assay was performed. Cervical cancer cells were transfected with sLZIP and the MMP-9 promoter reporter gene. Results showed that sLZIP up-regulates the promoter activity of MMP-9 in a dose-dependent manner in both HeLa and SiHa cells, compared with a control (Fig. 3a). We also examined the promoter activity of MMP-9 using siRNA for c-Jun (si-c-Jun). In si-c-Jun transfected cells, the promoter activity of MMP-9 was decreased, compared to sLZIP transfected cells (Fig. 3b). The 5'-flanking region of the MMP9 promoter contains two binding sites for AP-1 [3, 9]. c-Jun modulates the MMP-9 promoter activity by binding to the AP-1 sites in the MMP-9 promoter $[27,28]$. Therefore, the effect of c-Jun induced by SLZIP on MMP-9 promoter activity was examined using a luciferase reporter assay. Cells were transfected with the promoter reporter gene containing AP-1 binding sites. sLZIP increased the luciferase activity, whereas si-sLZIP down-regulated the luciferase activity in HeLa cells, compared with a control (Fig. 3c). Deletion constructs of the MMP-9 promoter were generated to confirm the binding site of c-Jun. HeLa cells were transfected with the c-Jun expression plasmid and the MMP-9 promoter deletion mutants. c-Jun increased the MMP-9 promoter activity by 2.5-fold, compared with a control; however, the MMP-9 promoter activity was reduced approximately 2 -fold in the AP-1 \#2 binding site deletion mutant, compared with the full-length MMP-9 promoter (Fig. 3d). To confirm these results, we generated a site-specific MMP-9 promoter mutant in the AP-1 \#2 biding site. 


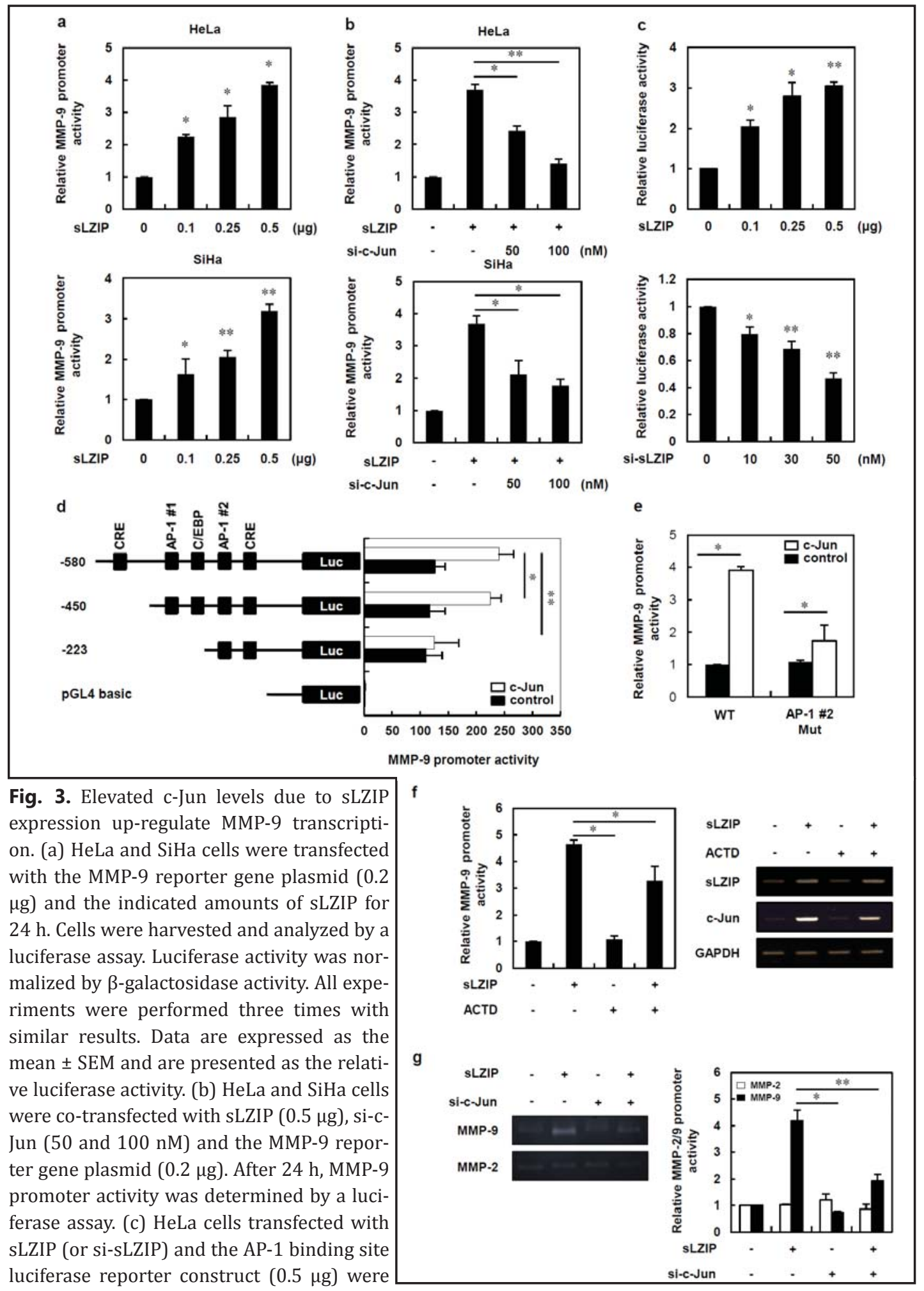
luciferase reporter construct $(0.5 \mu \mathrm{g})$ were 


\section{Cellular Physiology and Biochemistry}

Cell Physiol Biochem 2014;33:151-164

DOI: $10.1159 / 000356658$

(C) 2014 S. Karger AG, Basel

www.karger.com/cpb

Park et al.: Role of sLZIP in Migration and Invasion of Cervical Cancer Cells

determined after $24 \mathrm{~h}$. (f) HeLa cells were transfected with SLZIP $(0.5 \mu \mathrm{g})$ with or without the MMP-9 reporter gene $(0.2 \mu \mathrm{g})$ and treated with ACTD $(1 \mu \mathrm{g} / \mathrm{ml})$ for $2 \mathrm{~h}$. Results are expressed as the mean \pm SEM of three experiments performed in duplicate. (g) Gelatin zymography was used to examine the MMP-9 proteolytic activity. Supernatants were collected from transfected HeLa cells and cultured in serum-free medium for 48 $\mathrm{h}$, then subjected to $10 \%$ SDS-polyacrylamide gel electrophoresis. ${ }^{*} p<0.05,{ }^{* *} p<0.01$. All experiments were performed in triplicate and the bar represents the mean \pm SEM.

c-Jun increased MMP-9 promoter activity by 3.8-fold; however, MMP-9 promoter activity was reduced in the AP-1 \#2 binding site mutant (Fig. 3e). We next treated HeLa cells with the transcription inhibitor actinomycin D (ACTD). The promoter activity of MMP-9 was decreased by inhibition of sLZIP-induced c-Jun expression, compared to sLZIP transfected cells (Fig. 3f). The proteolytic activities of type IV collagenases were examined using gelatin zymography. Concentrated CM was obtained from HeLa cells transfected with sLZIP and si-cJun. Results showed that SLZIP increases the enzymatic activity of MMP-9; however, si-c-Jun decreases SLZIP-induced MMP-9 promoter activity, compared to sLZIP transfected CM (Fig. 3g). MMP-2 activity was not affected by SLZIP (Fig. 3g). These results indicate that sLZIP induces c-Jun expression, and elevated levels of c-Jun cause binding to the AP-1 binding site in the MMP-9 promoter, leading to the transcriptional activation of MMP-9 in cervical cancer cells.

sLZIP and c-Jun induce migration and invasion of cervical cancer cells

To examine whether sLZIP and c-Jun are involved in migration of cervical cancer cells, a wound healing assay was performed. CM was prepared from cells transfected with SLZIP and si-c-Jun. The rate of wound closure was increased by 4.5-fold in HeLa and SiHa cells treated with sLZIP CM, compared to a control (Fig. 4a and b). Cells treated with si-c-Jun exhibited reduced migration; however, migration was recovered by sLZIP, compared to sic-Jun transfected cells (Fig. 4a and b). We also investigated the effect of sLZIP and c-Jun on invasion of cervical cancer cells using a Matrigel invasion assay. HeLa and SiHa cells were cultured in serum-free DMEM and 30\% CM mixtures were placed in the lower chambers. As shown in Fig. 4c and d, sLZIP enhanced invasion of HeLa and SiHa cells. Cells treated with si-c-Jun exhibited a reduced degree of invasion; however, invasion was recovered by sLZIP, compared to si-c-Jun transfected cells (Fig. 4c and d). To examine whether sLZIP and c-Jun contribute to cell proliferation, cell viability was examined using an MTT assay. sLZIP and si-c-Jun did not affect the proliferation of cervical cancer cells, compared with a control (Fig. 4e). These results indicate that sLZIP and c-Jun play important roles in migration and invasion of cervical cancer cells.

Increased expression of SLZIP is involved in the aggressiveness of cervical cancer tissue

The relationship between expressions of SLZIP and MMP-9 in cervical tissues was investigated using immunohistochemical analysis. Expressions of sLZIP and MMP-9 were examined using a tissue microarray containing 5 normal cervical tissues, 50 squamous cell carcinomas, and 5 metastatic carcinoma samples from lymph nodes. MMP-9 is overexpressed in many tumors $[4,29]$. Results showed that SLZIP and MMP-9 are highly expressed in squamous cell carcinomas, compared with the expression levels of sLZIP and MMP-9 in normal cervical tissues (Fig. 5a). Lymph node metastatic tissues exhibited higher expression levels of sLZIP and MMP-9, compared to normal tissues (Fig. 5a). These results indicate that the expression levels of sLZIP and MMP-9 are correlated. Quantitative analytical results showed that sLZIP expression is significantly increased in tumor specimens, compared with normal cervical tissues (Fig. 5b). These findings indicate that overexpression of sLZIP causes up-regulation of MMP-9 expression, leading to aggressive tumor invasion and metastasis in cervical cancer. 


\section{Cellular Physiology $\quad$ Cell Physiol Biochem 2014;33:151-164

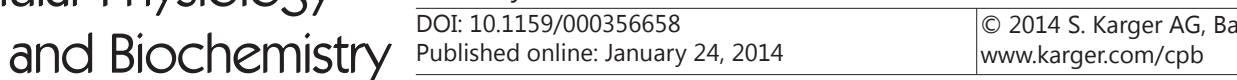

Fig. 4. sLZIP and c-Jun induce migration and invasion of cervical cancer cells. (a and b) HeLa and SiHa cells were transfected with the mock, and sLZIP $(2 \mu \mathrm{g})$ or si-c-Jun $(100 \mathrm{nM})$. Seeded cells in 6 -well plates were scratched and incubated in 30\% CM mixture for $24 \mathrm{~h}$. Representative images of wound healing were taken at the indicated time points. Data are expressed as the mean \pm SEM. (c and d) Five hundred $\mu \mathrm{l}$ of $1 \times 10^{5}$ cells were cultured in serum free DMEM and incubated in 30\% CM mixture for $48 \mathrm{~h}$. After incubation, non-invasive cells were removed from the chamber and invasive cells were washed, fixed and stained with Diff-Quick staining solution. Results are presented as the fold change of invasion relative to control. (e) Cells were transfected with the mock, sLZIP $(2 \mu \mathrm{g})$ and si-c-Jun (100 nM). After $24 \mathrm{~h}$, cells were re-seeded in 96-well plates for the indicated time points. Cell proliferation was examined by a MTT assay. Data are presented as the fold change of proliferation relative to 0 day. All measurements were performed in triplicate. ${ }^{*} p<0.05,{ }^{* *} p<0.01$. All experiments were performed in triplicate and the bar represents the mean \pm SEM.
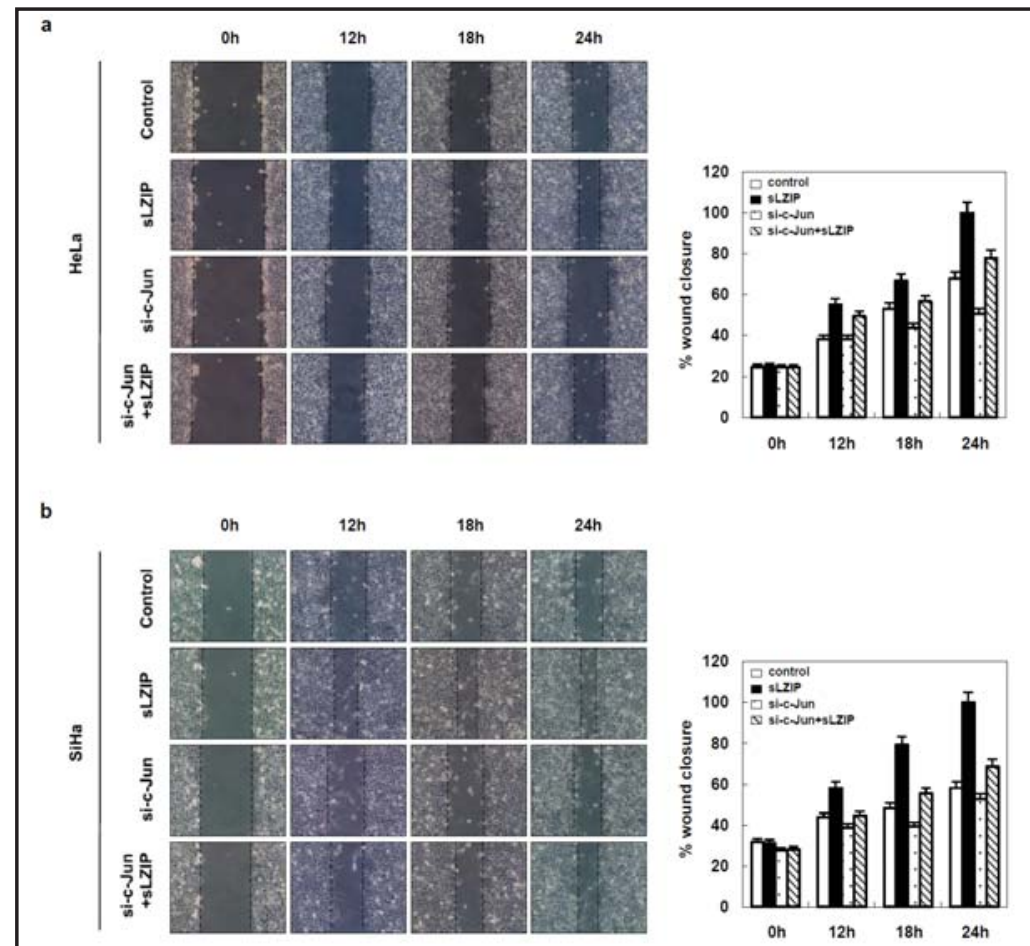

c
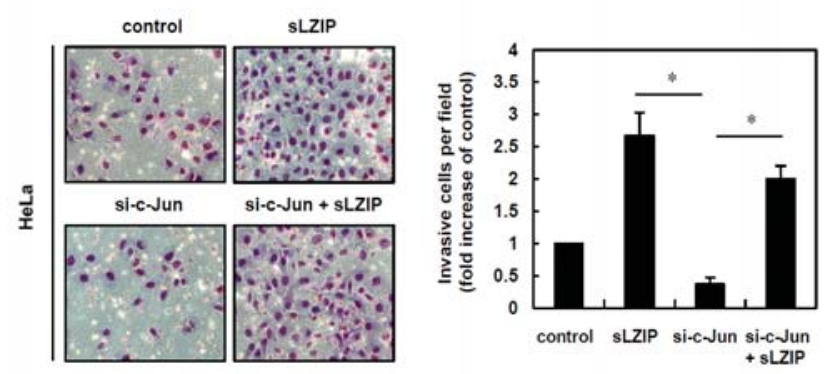

d
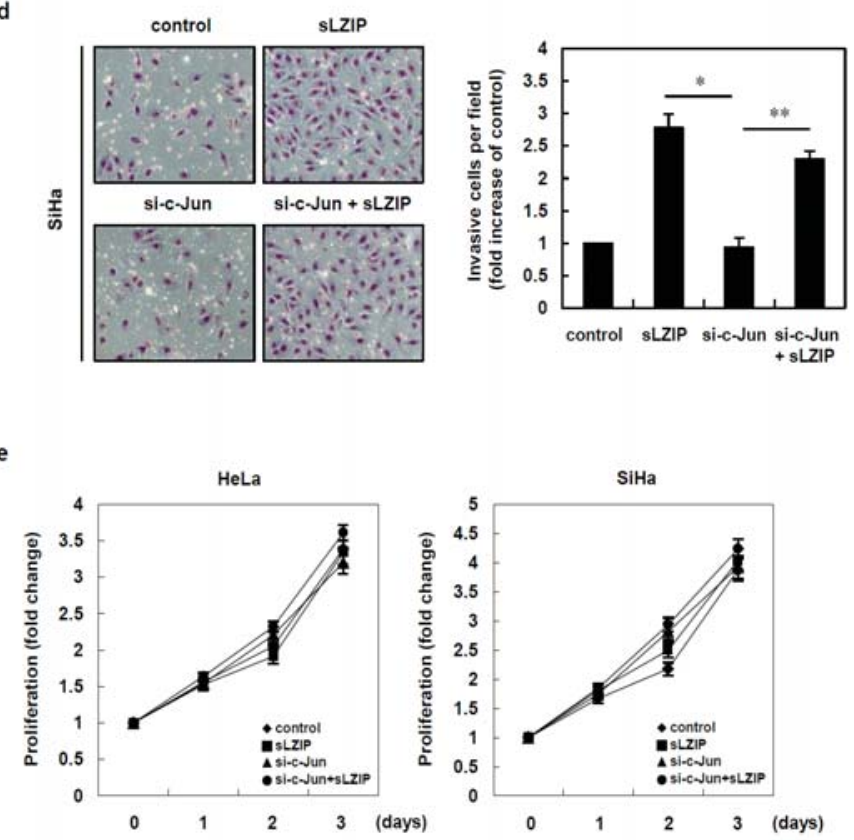


\section{Cellular Physiology and Biochemistry}

Cell Physiol Biochem 2014;33:151-164

DOI: 10.1159/000356658

Publisned onIIne: January 24, 2014

S. Karger AG, Basel

Park et al.: Role of sLZIP in Migration and Invasion of Cervical Cancer Cells

Fig. 5. Expressions of sLZIP and MMP-9 are elevated in cervical tumors. (a) The expression levels of sLZIP and MMP-9 were analyzed by immunohistochemistry using antisLZIP and anti-MMP-9 antibodies in normal cervixes $(n=5)$, squamous cell carcinomas $(n=50)$, and lymph node metastatic carcinomas of the cervix $(n=5)$. Representative images of immunostaining are shown (20fold magnification). Scale bar, $20 \mu \mathrm{m}$. (b) sLZIP expression was examined by immunohistochemical staining of tissue arrays representing 60 specimens. Stained cells were counted and analyzed quantitatively. The data was expressed in order of intensity of sLZIP expression. Horizontal lines represent the median levels, with the lower and upper, respectively. ${ }^{*} p<0.05,{ }^{* *} p<0.01$ All experiments were performed in triplicate and the bar represents the mean \pm SEM.

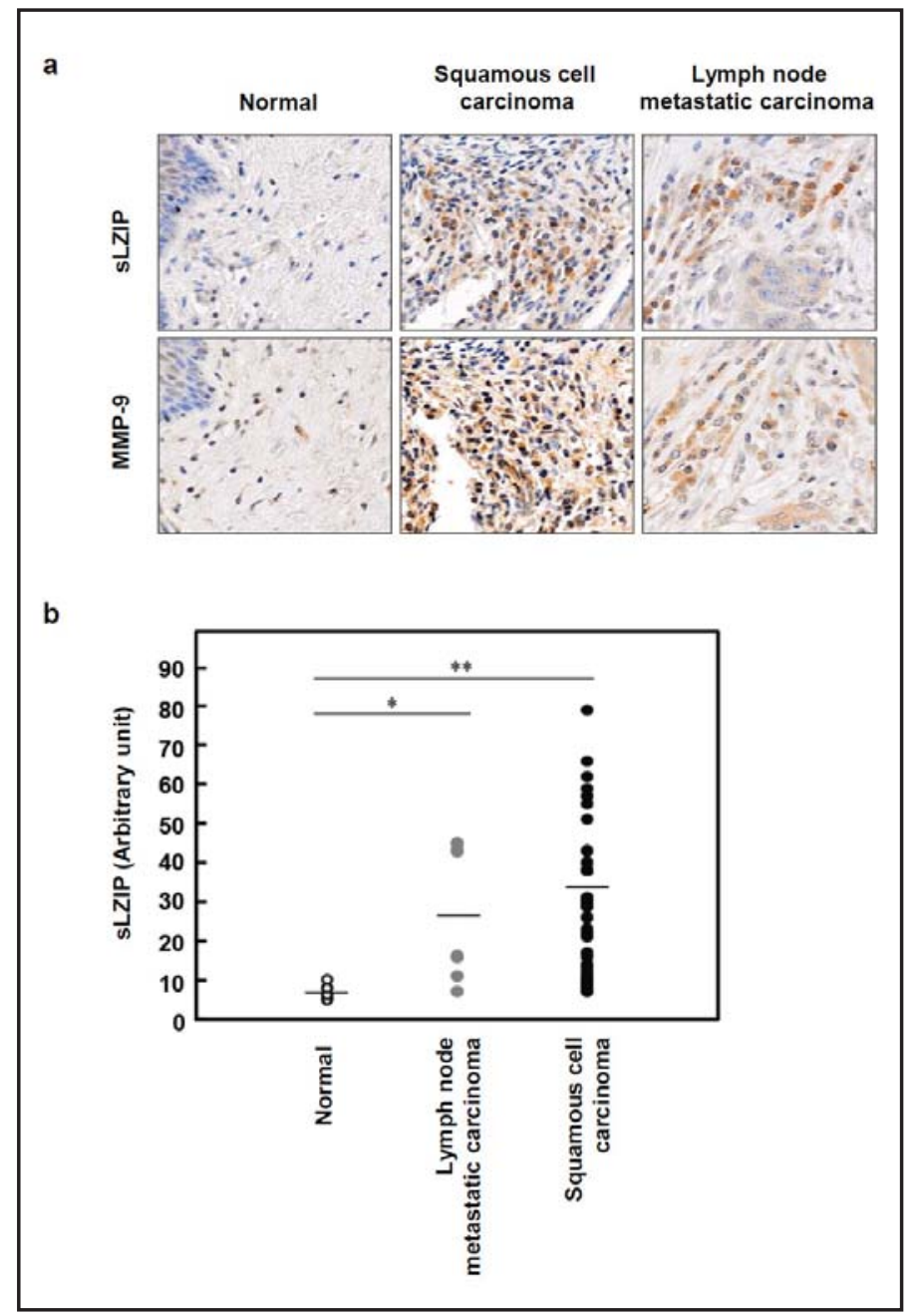

\section{Discussion}

As an early event in the metastatic cascade, degradation of the basement membrane causes invasion and metastasis of cancer cells. Because MMP-9 destroys type IV collagen, which is the major structural protein of both ECM and basement membrane, expression of MMP-9 is an indicator of diagnosis and for prognosis in various cancers [30, 31]. Invasion of human tumor cells through the basement membrane is a result of MMP-9 activity [10, 32]. Additionally, enhanced expression of MMP-9 in cancers and a role for MMP-9 in tumor progression and metastasis have been verified [29, 33, 34]. We have previously reported that sLZIP binds directly to the CRE region of the MMP-9 promoter, resulting in enhancement of migration and invasion of cervical cancer cells [26]. In this study, sLZIP was found to upregulate expression of c-Jun in cervical cancer cells. sLZIP induced c-Jun expression at the transcriptional level in HeLa and SiHa cells, leading to enhancement of MMP-9 expression and migration of cervical cancer cells. These results indicate that there exists an additional regulatory mechanism for MMP-9 expression relating to sLZIP. These results are evidence that sLZIP is involved in cervical cancer development and metastasis.

Transcription factor AP-1 is a heterodimeric protein composed of c-Fos, c-Jun, and ATF subunits. Elevated c-Jun expression and AP-1 activity have been detected in various cancer types [11], and activation of AP-1 for regulation of targets occurs via c-Jun phosphorylation through the c-Jun activation signaling pathways [28]. c-Jun also interacts with other transcription factors to regulate their expression in many biological processes $[11,35]$. Therefore, regulation of c-Jun expression and c-Jun activation signaling is important in 


\section{Cellular Physiology and Biochemistry}

Cell Physiol Biochem 2014;33:151-164

DOI: $10.1159 / 000356658$

(C) 2014 S. Karger AG, Basel

www.karger.com/cpb

Park et al.: Role of sLZIP in Migration and Invasion of Cervical Cancer Cells

cancer development. There are several c-Jun regulatory proteins, including GR, C/EBP $\alpha$, and GSK3 [36-38]. Among these regulators, GR represses c-Jun expression in mouse fibroblasts [36]. Since sLZIP is known as a negative regulator of GR [24], sLZIP is probably involved in c-Jun expression via a GR-mediated indirect pathway.

MMP-9 is one of the target molecules of c-Jun. There are binding sites for AP-1 in the MMP-9 promoter. SLZIP increased the promoter and enzymatic activities of MMP-9 via induction of c-Jun. Elevated c-Jun levels due to SLZIP expression causes c-Jun to bind to the distal AP-1 site in the MMP-9 promoter. The effect of c-Jun on transcription of MMP-9 was verified using the transcription inhibitor ACTD. Inhibition of c-Jun transcription caused a $30 \%$ decrease in the MMP-9 promoter activity, compared to sLZIP alone, indicating that sLZIP- induced c-Jun is involved in regulation of MMP-9 expression. Migration of cervical cancer cells treated with SLZIP transfected CM was enhanced, but treatment with si-c-Jun $\mathrm{CM}$ caused inhibition of this migration. However, migration was recovered in the presence of sLZIP CM. Results from an invasion assay were consistent with wound healing assay results. Enhanced migration and invasion of cervical cancer cells indicate that sLZIP is involved in cell migration during cervical cancer progression. In addition, immunohistochemical results indicate that elevated expression of sLZIP in tumors can serve as a marker for metastatic cervical cancer. sLZIP is an important regulator of cell migration and invasion in cervical cancer. sLZIP up-regulates c-jun expression and elevated levels of c-Jun due to sLZIP subsequently activate transcription and proteolytic activity of MMP-9, leading to promotion of metastasis during cervical cancer progression. These results suggest that sLZIP can act as a therapeutic target for cervical cancer.

\section{Acknowledgments}

This work was supported by the Korea University Grant and the Basic Research Laboratory Program (2009-0087099) through the National Research Foundation of Korea (NRF) funded by the Ministry of Education, Science and Technology.

\section{Conflicts of Interest}

We confirm that all authors fulfill all conditions required for authorship. We also confirm that there is no potential conflict of interest as described in the Instruction for Authors. All authors have read and approved the manuscript.

\section{References}

1 Chakraborti S, Mandal M, Das S, Mandal A, Chakraborti T: Regulation of matrix metalloproteinases: An overview. Mol Cell Biochem 2003;253:269-285.

-2 Johansson N, Ahonen M, Kahari VM: Matrix metalloproteinases in tumor invasion. Cell Mol Life Sci 2000;57:5-15.

-3 Visse R, Nagase H: Matrix metalloproteinases and tissue inhibitors of metalloproteinases: Structure, function, and biochemistry. Circ Res 2003;92:827-839.

4 Egeblad M, Werb Z: New functions for the matrix metalloproteinases in cancer progression. Nat Rev Cancer 2002;2:161-174.

-5 Rao JS, Yamamoto M, Mohaman S, Gokaslan ZL, Fuller GN, Stetler-Stevenson WG, Rao VH, Liotta LA, Nicolson GL, Sawaya RE: Expression and localization of 92 kda type iv collagenase/gelatinase b (mmp-9) in human gliomas. Clin Exp Metastasis 1996;14:12-18.

6 Chang C, Werb Z: The many faces of metalloproteases: Cell growth, invasion, angiogenesis and metastasis. Trends Cell Biol 2001;11:S37-43. 


\section{Cellular Physiology and Biochemistry}

Cell Physiol Biochem 2014;33:151-164

\begin{tabular}{l|l}
\hline DOI: $10.1159 / 000356658$ & (C) 2014 S. Karger AG, Basel
\end{tabular}

Park et al.: Role of sLZIP in Migration and Invasion of Cervical Cancer Cells

7 Sehgal G, Hua J, Bernhard EJ, Sehgal I, Thompson TC, Muschel RJ: Requirement for matrix metalloproteinase- 9 (gelatinase b) expression in metastasis by murine prostate carcinoma. Am J Pathol 1998;152:591-596.

8 Hua J, Muschel RJ: Inhibition of matrix metalloproteinase 9 expression by a ribozyme blocks metastasis in a rat sarcoma model system. Cancer Res 1996;56:5279-5284.

-9 Bergers G, Brekken R, McMahon G, Vu TH, Itoh T, Tamaki K, Tanzawa K, Thorpe P, Itohara S, Werb Z, Hanahan D: Matrix metalloproteinase-9 triggers the angiogenic switch during carcinogenesis. Nat Cell Biol 2000;2:737-744.

10 Suzuki T, Hashimoto Y, Okuno H, Sato H, Nishina H, Iba H: High-level expression of human c-jun gene causes cellular transformation of chicken embryo fibroblasts. Jpn J Cancer Res 1991;82:58-64.

11 Vogt PK, Bos TJ: Jun: Oncogene and transcription factor. Adv Cancer Res 1990;55:1-35.

12 Xu J, Rodriguez D, Petitclerc E, Kim JJ, Hangai M, Moon YS, Davis GE, Brooks PC: Proteolytic exposure of a cryptic site within collagen type iv is required for angiogenesis and tumor growth in vivo. J Cell Biol 2001;154:1069-1079.

13 Schreiber M, Kolbus A, Piu F, Szabowski A, Mohle-Steinlein U, Tian J, Karin M, Angel P, Wagner EF: Control of cell cycle progression by c-jun is p53 dependent. Genes Dev 1999;13:607-619.

14 Johnson R, Spiegelman B, Hanahan D, Wisdom R: Cellular transformation and malignancy induced by ras require c-jun. Mol Cell Biol 1996;16:4504-4511.

-15 Chen SY, Cai C, Fisher CJ, Zheng Z, Omwancha J, Hsieh CL, Shemshedini L: C-jun enhancement of androgen receptor transactivation is associated with prostate cancer cell proliferation. Oncogene 2006;25:72127223.

16 Zhang G, Luo X, Sumithran E, Pua VS, Barnetson RS, Halliday GM, Khachigian LM: Squamous cell carcinoma growth in mice and in culture is regulated by c-jun and its control of matrix metalloproteinase- 2 and -9 expression. Oncogene 2006;25:7260-7266.

17 Kanzler S, Meyer E, Lohse AW, Schirmacher P, Henninger J, Galle PR, Blessing M: Hepatocellular expression of a dominant-negative mutant tgf-beta type ii receptor accelerates chemically induced hepatocarcinogenesis. Oncogene 2001;20:5015-5024.

18 Knight B, Yeoh GC, Husk KL, Ly T, Abraham LJ, Yu C, Rhim JA, Fausto N: Impaired preneoplastic changes and liver tumor formation in tumor necrosis factor receptor type 1 knockout mice. J Exp Med 2000;192:18091818.

19 Sharma P, Kumar S, Kundu GC: Transcriptional regulation of human osteopontin promoter by histone deacetylase inhibitor, trichostatin a in cervical cancer cells. Mol Cancer 2010;9:178.

20 Loesch M, Zhi HY, Hou SW, Qi XM, Li RS, Basir Z, Iftner T, Cuenda A, Chen G: P38gamma mapk cooperates with c-jun in trans-activating matrix metalloproteinase 9. J Biol Chem 2010;285:15149-15158.

21 Lu R, Yang P, O'Hare P, Misra V: Luman, a new member of the creb/atf family, binds to herpes simplex virus vp16-associated host cellular factor. Mol Cell Biol 1997;17:5117-5126.

22 Luciano RL, Wilson AC: N-terminal transcriptional activation domain of lzip comprises two lxxll motifs and the host cell factor-1 binding motif. Proc Natl Acad Sci U S A 2000;97:10757-10762.

-23 Raggo C, Rapin N, Stirling J, Gobeil P, Smith-Windsor E, O'Hare P, Misra V: Luman, the cellular counterpart of herpes simplex virus vp16, is processed by regulated intramembrane proteolysis. Mol Cell Biol 2002;22:5639-5649.

24 Kang H, Kim YS, Ko J: A novel isoform of human lzip negatively regulates the transactivation of the glucocorticoid receptor. Mol Endocrinol 2009;23:1746-1757.

-25 Jang SY, Jang SW, Ko J: Regulation of adp-ribosylation factor 4 expression by small leucine zipper protein and involvement in breast cancer cell migration. Cancer Lett 2012;314:185-197.

-26 Kang H, Jang SW, Ko J: Human leucine zipper protein slzip induces migration and invasion of cervical cancer cells via expression of matrix metalloproteinase-9. J Biol Chem 2011;286:42072-42081.

-27 Crowe DL, Tsang KJ, Shemirani B: Jun n-terminal kinase 1 mediates transcriptional induction of matrix metalloproteinase 9 expression. Neoplasia 2001;3:27-32.

28 Hong IK, Jin YJ, Byun HJ, Jeoung DI, Kim YM, Lee H: Homophilic interactions of tetraspanin cd151 upregulate motility and matrix metalloproteinase-9 expression of human melanoma cells through adhesiondependent c-jun activation signaling pathways. J Biol Chem 2006;281:24279-24292.

-29 Roomi MW, Monterrey JC, Kalinovsky T, Rath M, Niedzwiecki A: Patterns of mmp-2 and mmp-9 expression in human cancer cell lines. Oncol Rep 2009;21:1323-1333. 


\section{Cellular Physiology $\quad$ Cell Physiol Biochem 2014;33:151-164 \\ and Biochemistry \begin{tabular}{l|l} 
DOI: 10.1159/000356658 \\
Publisned onine: January 24, 2014 & $\begin{array}{l}\text { O 2014 S. Karger AG, } \\
\text { www.karger.com/cpb }\end{array}$
\end{tabular}}

Park et al.: Role of sLZIP in Migration and Invasion of Cervical Cancer Cells

-30 Liotta LA, Tryggvason K, Garbisa S, Hart I, Foltz CM, Shafie S: Metastatic potential correlates with enzymatic degradation of basement membrane collagen. Nature 1980;284:67-68.

-31 Sato T, Sakai T, Noguchi Y, Takita M, Hirakawa S, Ito A: Tumor-stromal cell contact promotes invasion of human uterine cervical carcinoma cells by augmenting the expression and activation of stromal matrix metalloproteinases. Gynecol Oncol 2004;92:47-56.

-32 Stetler-Stevenson WG: Type iv collagenases in tumor invasion and metastasis. Cancer Metastasis Rev 1990;9:289-303.

-33 Fishman DA, Bafetti LM, Banionis S, Kearns AS, Chilukuri K, Stack MS: Production of extracellular matrix-degrading proteinases by primary cultures of human epithelial ovarian carcinoma cells. Cancer 1997;80:1457-1463.

-34 Schmalfeldt B, Prechtel D, Harting K, Spathe K, Rutke S, Konik E, Fridman R, Berger U, Schmitt M, Kuhn W, Lengyel E: Increased expression of matrix metalloproteinases (mmp)-2, mmp-9, and the urokinase-type plasminogen activator is associated with progression from benign to advanced ovarian cancer. Clin Cancer Res 2001;7:2396-2404.

35 Xie W, Feng Q, Su Y, Dong B, Wu J, Meng L, Qu L, Shou C: Transcriptional regulation of pes1 expression by c-jun in colon cancer. PLoS One 2012;7:e42253.

-36 Wei P, Inamdar N, Vedeckis WV: Transrepression of c-jun gene expression by the glucocorticoid receptor requires both ap-1 sites in the c-jun promoter. Mol Endocrinol 1998;12:1322-1333.

-37 Rangatia J, Vangala RK, Treiber N, Zhang P, Radomska H, Tenen DG, Hiddemann W, Behre G: Downregulation of c-jun expression by transcription factor c/ebpalpha is critical for granulocytic lineage commitment. Mol Cell Biol 2002;22:8681-8694.

-38 Wei W, Jin J, Schlisio S, Harper JW, Kaelin WG Jr: The v-jun point mutation allows c-jun to escape gsk3dependent recognition and destruction by the fbw7 ubiquitin ligase. Cancer Cell 2005;8:25-33. 